\title{
Fire-mediated niche-separation between two sympatric small mammal species
}

\author{
EMILY J. MOWAT, ${ }^{1}$ JONATHAN K. WEBB ${ }^{2}$ AND MATHEW S. CROWTHER ${ }^{3 \star}$ \\ ${ }^{1}$ School of Biological Sciences, University of Sydney, Sydney, ${ }^{2}$ School of the Environment, University of \\ Technology Sydney, Broadway, New South Wales, Australia, and ${ }^{3}$ School of Biological Sciences, Building \\ A08, University of Sydney, Sydney, NSW 2006, Australia (Email: mathew.crowther@sydney.edu.au)
}

\begin{abstract}
Fire is a key ecological process influencing the population dynamics of small mammals. Whilst shifting competitive advantage amongst small mammal species following a single fire event is well-documented, there has been little investigation of the potential influence of fire frequency on small mammal interspecific interactions. In this study, we investigated the effect of fire frequency on the abundance of two small dasyurid mammals, Antechinus stuartii and $A$. flavipes, which occur sympatrically in some parts of their range. The two antechinus species are known to have different habitat preferences, so it is possible that fire regimes may promote their coexistence in areas of sympatry by altering vegetation structure. To investigate this possibility, we estimated the abundance of both species using replicate sites which differed in the number of times burnt (1-4) during the last four decades, but with identical time-since-fire. Proportionally, we captured greater numbers of $A$. stuartii in less frequently burnt sites and greater numbers of $A$. flavipes in more-frequently burnt sites. Hence, fire may mediate niche-separation between these two species. To clarify further this pattern of response to fire frequency, we investigated which structural habitat variables differed between fire frequencies, and compared antechinus abundances with structural vegetation characteristics. We found a trend for lower ground cover density under higher fire frequencies. This offers one potential explanation of the patterns of abundance that we observed. Our study provided insights into the complexities of small mammal responses to fire, and strongly suggests that fire could mediate competitive interactions between species.
\end{abstract}

Key words: dasyurid, fire frequency, fire regime, interspecific competition, vegetation structure.

\section{INTRODUCTION}

Fire plays an important role in shaping the landscapes and biota of ecosystems worldwide (Whelan 1995; Bond \& Van Wilgen 1996; DeBano et al. 1998; Bond $\&$ Keeley 2005). Rather than focusing on the effects of any single fire event, ecologists are increasingly realizing the importance of fire regimes- the pattern of fire occurrence over time (Keith et al. 2002b; Kelly et al. 2012). The fire regime concept recognizes that a fire is one in a series of recurring disturbances affecting a species, population, or community (Whelan 1995). The three main components of fire regimes are frequency, intensity, and season of occurrence (Gill 1975; Gill et al. 1981), which are highly interlinked (Fox \& Fox 1987). All three components influence the composition and structure of both plant and animal communities (Bradstock et al. 2002).

Fire frequency, the number of fires occurring within a given time period, can have significant effects

${ }^{\star}$ Corresponding author.

Accepted for publication June 2014.

(C) 2014 The Authors

Austral Ecology (C) 2014 Ecological Society of Australia on ecological communities (Andersen et al. 2005; Bradstock 2008). For example, if inter-fire intervals are short, the critical habitat features required by a species may not recover before the next fire event (Cary 2005), or a critical life stage may not be attained (Whelan et al. 2002). As a result, the population of that species may decline or disappear from the community (Whelan 1995; Andersen et al. 2005).

In general, frequent fire in Australian sclerophyll forests leads to simplification of vegetation structure (Gilbert 1959; Christensen et al. 1981). This results from a reduction in shrub cover and mid-storey plants, lower litter accumulation, reduced log cover, and the development of an open understory dominated by grasses, herbaceous plants and ferns (Gill 1975; Siddiqi et al. 1976; Bradfield 1981; Bradstock 1981; Christensen et al. 1981; Fox \& Fox 1987; Cary \& Morrison 1995; Morrison et al. 1995; Tasker \& Dickman 2004; Spencer \& Baxter 2006).

Interspecific competition plays an important role in structuring small mammal communities (Abramsky et al. 1979; Dueser \& Hallett 1980; Kelt et al. 1995). Competition between small mammal 
species for resources such as food or habitat can influence their distribution and abundance (Hersteinsson \& MacDonald 1992). In order to reduce or avoid interspecific competition, sympatric species may partition resources (Schoener 1974). This can lead to differential habitat use (Higgs \& Fox 1993) or dietary shifts (Luo \& Fox 1996) among competing species (M'Closkey \& Fieldwick 1975; Meserve 1981; Goodyear 1992). Habitat partitioning, rather than food resource partitioning, tends to be the primary mechanism allowing coexistence in small mammal communities (Schoener 1974; Rosenzweig et al. 1975; Grant 1978).

Competition between small mammal species can influence community composition after fire (Higgs \& Fox 1993; Monamy \& Fox 2000). Time-since-fire studies in different parts of the world have demonstrated a relatively consistent succession of small mammal species that occurs post fire (e.g. Quinn 1979; Fox \& McKay 1981; Fox 1982a, 1983, 1990; Wirtz et al. 1988; Collins \& Wallace 1990; Vieira 1999; Briani et al. 2004). Rather than a sequential replacement of species, there is a shifting pattern of dominance as species increase and then decline in their relative abundances (Friend 1999). This pattern of succession mirrors postfire changes in the structure of the vegetation (Krefting \& Ahlgren 1974; Price \& Waser 1984; Fox \& Fox 1987; Ojeda 1989; Arrizabalaga et al. 1993; Fons et al. 1993), and is related to species food, shelter, and nesting requirements (Friend 1993). Small mammal species enter the community when their habitat requirements are met, increase to peak abundance when optimal conditions for their survival are reached, and then decline as conditions become suboptimal and their competitive ability is reduced (Fox 1982a).

Whilst numerous studies have investigated shifting competitive advantage amongst small mammal species following a single fire event, few have examined the effects of fire frequency on small mammal populations (Irvin et al. 2003; Andersen et al. 2005). Fire frequency primarily influences the composition of small mammal communities through its effects on vegetation structure (Fox \& Fox 1987), which provides or moderates key habitat requirements such as food, shelter, and nest sites (Friend 1993; Whelan 1995). Frequent fire may therefore make habitats less suitable for some species and more suitable for others (Hobbs 2002; Keith et al. 2002a).

In eastern Australia, two closely related small, insectivorous dasyurid marsupials, the brown antechinus (Antechinus stuartii) and the yellow-footed antechinus (Antechinus flavipes), rarely occur in sympatry (Crowther 2008; Crowther \& Braithwaite 2008). The two species utilize different habitat types; $A$. flavipes occurs in open habitats, with much of its range extending over inland areas (Crowther 2002). In contrast, $A$. stuartii prefers dense, complex understory and is restricted to coastal areas (Knight \& Fox 2000; Crowther \& Braithwaite 2008). The two species are likely to compete for food and shelter, given that they are similar in size (Fox 1982b), and have similar diets and nesting requirements (Crowther 2008; Crowther \& Braithwaite 2008).

Potentially, by altering vegetation structure, fire regimes may promote coexistence of Antechinus in areas of sympatry. To explore this question, we estimated the abundance of $A$. flavipes and $A$. stuartii at sites with different fire histories in Yengo National Park, NSW, one of the few areas where the two species co-occur (Crowther 2008; Crowther \& Braithwaite 2008). We predicted that $A$. flavipes would occur in greater numbers at sites with higher fire frequency (with sparse vegetation) whereas $A$. stuartii would favour lessfrequently burned sites with denser vegetation.

\section{METHODS}

\section{Study sites}

Our study sites were located in southern Yengo National Park $\left(151^{\circ} 1^{\prime} 31^{\prime \prime} \mathrm{E}, 33^{\circ} 13^{\prime} 24^{\prime \prime} \mathrm{S}\right)$, in eastern New South Wales, Australia (Fig. 1). Yengo National Park is located within the Sydney Basin Bioregion, characterized by a temperate climate with warm summer temperatures and no dry season (NPWS 2003). The mean annual temperature is $16^{\circ} \mathrm{C}$, and the region receives $1000 \mathrm{~mm}$ annual rainfall on average.

The region is dominated by Sydney Hinterland Dry Sclerophyll Forest. Vegetation types present on the study sites included Sydney Hinterland Rocky Yellow Bloodwood Woodland (dominated by Corymbia eximia and Angophora bakeri) Sydney Hinterland Exposed Red Bloodwood-Stringybark Forest (predominantly Corymbia gummifera and Eucalyptus sparsifolia), and Sydney Hinterland Peppermint-Apple Forest (Angophora costata, Syncarpia glomulifera subsp. glomulifera, Eucalyptus piperita and C. gummifera). All sites contained a shrubby understory, characterized by various combinations of Leptospermum trinervium, Banksia spinulosa var. collina, Persoonia linearis, P. levis, Gompholobium latifolium and Acacia linifolia. Ground vegetation comprised a variety of grass and forb species, including Lomandra glauca, Cyathochaeta diandra, Entolasia stricta, Pteridium esculentum, Dianella caerulea, Lomatia silaifolia and Platysace linearifolia.

We chose 12 study sites that had experienced one, two, three or four wildfires since 1972, with three replicate sites for each fire frequency (Fig. 1). To control for time-since-fire, we chose sites that all last burned during a wildfire in the summer of 2002-2003. Fire history was determined from NSW National Parks and Wildlife Service (NPWS) and Department of Environment, Climate Change and Water (DECC) fire records (Hammill \& Bradstock 2008).

All study sites were located on ridge tops (elevation $=240$ $324 \mathrm{~m}$ above sea level) to reduce any confounding effects of topography. The restriction of study sites to ridge tops was also necessary because fires burn with predictability on ridge tops, but often leave unburned patches of vegetation in creeks and gullies (Whelan 1995).

(C) 2014 The Authors

Austral Ecology (C) 2014 Ecological Society of Australia 


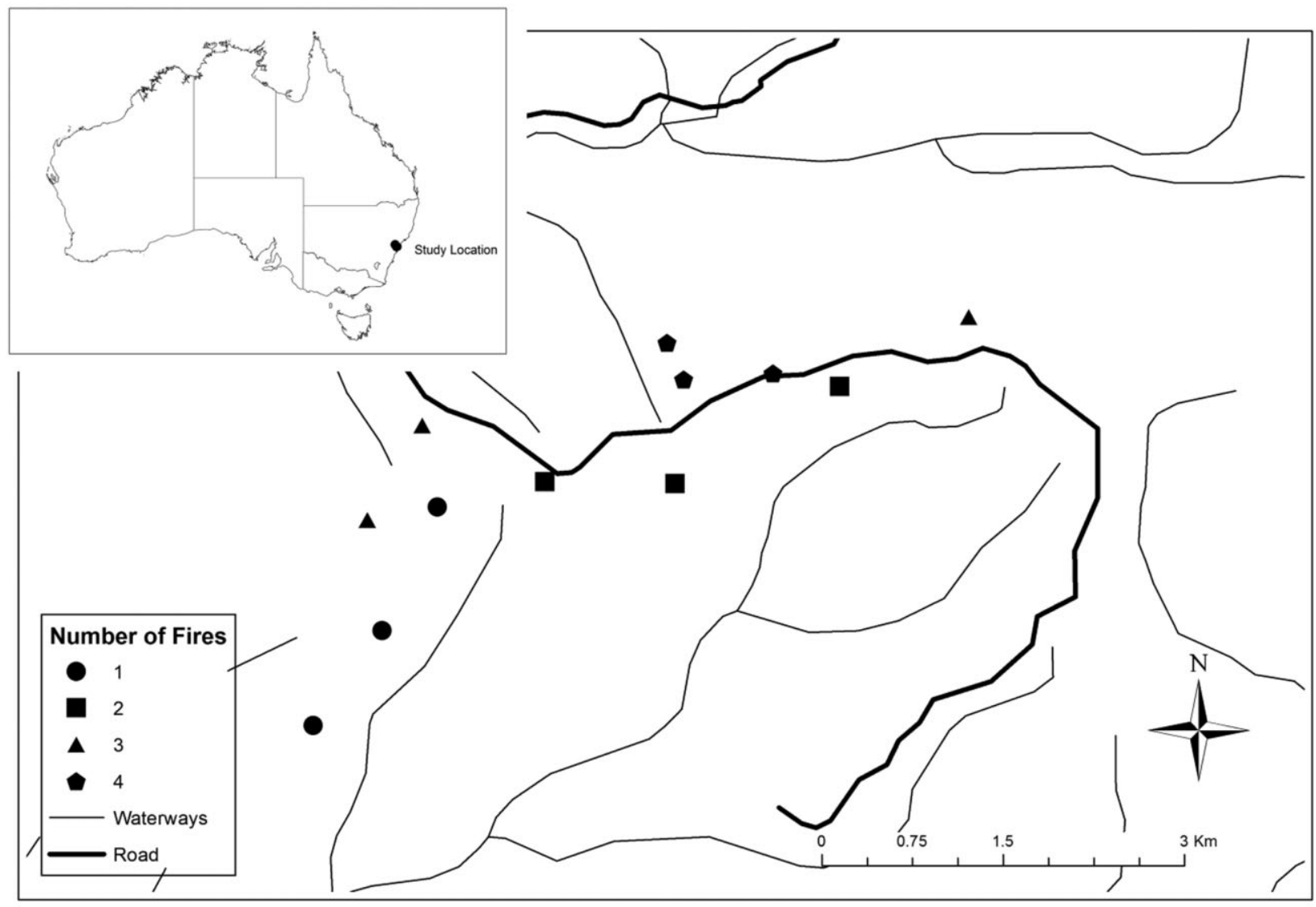

Fig. 1. Map of study sites and their fire frequency. Each site had experienced one, two, three or four wildfires since 1972, with three replicate sites for each fire frequency.

\section{Trapping}

We carried out three trapping sessions at 12 sites between April and August 2010. At each site, 25 aluminium Elliott traps $(33 \times 10 \times 10 \mathrm{~cm}$, Elliott Scientific Equipment, Upwey, Victoria), each spaced 5-10 m apart along a $250 \mathrm{~m}$ linear transect, were opened for three consecutive nights. We placed traps under shelter, along logs, or along animal runways, and baited them with a mixture of rolled oats, peanut butter, and honey. We provided each trap with non-absorbent cotton wool for bedding, and placed the trap inside a plastic bag to protect animals from inclement weather. We checked traps within $2 \mathrm{~h}$ of sunrise and recorded the species, and sex of all captured animals. We marked each animal with a unique ear clip (a $2 \mathrm{~mm}$ notch) to allow identification of recaptured individuals, and released it at the point of capture.

\section{Vegetation structure}

Vegetation structural characteristics were sampled within four $5 \times 5 \mathrm{~m}$ quadrats, which we established at four trap points evenly spaced along the transect. We visually estimated the percentage cover of canopy, shrubs, ground cover, grass, rock and leaf litter (to the nearest 5\%). Litter depth was measured at four random points within the quadrat and the average measurement taken. We counted the number of trees, grass trees (Xanthorrhoea spp.) and nectar-producing plants within the quadrat. We measured the diameter at breast height $(\mathrm{DBH})$ of the three trees closest to the centre of the quadrat, and from these measurements we calculated the mean tree $\mathrm{DBH}$. We also calculated the mean diameter of all $\operatorname{logs}(>10 \mathrm{~cm}$ in diameter) present in the quadrat. We measured tree $\mathrm{DBH}$ and $\log$ diameter using a tape measure to determine the circumference; we then divided the resulting number by pi $(\pi)$ to determine the diameter. Mean shrub height was established by measuring a representative sample of shrubs within the quadrat. The number of hollowbearing trees that were visible from the centre of the quadrat was counted; these did not have to be within the quadrat itself.

Horizontal vegetation density was estimated using a $20 \times 50 \mathrm{~cm}$ checkered coverboard made up of $10 \times 10 \mathrm{~cm}$ squares (after Fox \& Fox 1984). The board was held in the centre of the quadrat, and we counted how many squares on the board were obscured by vegetation from a distance of $5 \mathrm{~m}$. This was done for the vegetation layers $0-0.2 \mathrm{~m}, 0.2-$ $0.5 \mathrm{~m}, 0.5-1 \mathrm{~m}, 1-1.5 \mathrm{~m}$ and $1.5-2 \mathrm{~m}$, and was repeated in all four compass directions from the centre of the quadrat. 
Estimates were made at the same height above the ground as the vegetation stratum of interest.

For each habitat variable, we averaged the values obtained for each quadrat to yield a site value, apart from count data (number of trees, grass trees, hollow-bearing trees and nectar-producing plants) which we summed. Finally, we counted the numbers of hollow logs, solid logs and standing dead trees present within 5 meters either side of the entire length of the transect.

\section{Data analyses}

\section{Trapping data}

We estimated abundances of small mammals using the minimum number known to be alive (MNKTBA) method (Krebs, 1966). To investigate the effect of fire frequency on patterns of relative abundance of the two co-occurring antechinus species, we performed a chi-square test using a contingency table in JMP version 5.0.1a to compare the relative abundance of each species between different fire frequencies.

In order to determine the habitat variables that best explained the abundance of each small mammal species, we carried out model selection based on an informationtheoretic approach (Burnham \& Anderson 2002). We first used a Pearson's correlation to check for correlations between habitat variables. Where two variables had a correlation coefficient $\geq 0.7$, they were considered to be proxies of one another (Green 1979) and the variable that we determined to be less likely to be important to small mammal habitat (Knight \& Fox 2000) was excluded from further analysis.

The data for the remaining variables was standardized to have a mean of 0 and a standard deviation of 1 so that variables of different scales could be compared directly to one another in subsequent analysis. We used the R statistical package ( $\mathrm{R}$ Project for Statistical Computing release 2.11.1; http://www.r-project.org) for all habitat modelling. For each small mammal species, we used a generalized linear model (GLM) with a Poisson's distribution to test the relationship between abundance and each explanatory habitat variable. We ranked each of the resulting univariate models based on the Akaike Information Criterion (AIC, Akaike 1983).

We reduced the number of model variables to a manageable subset by selecting the nine variables that had the lowest AIC values. We then applied a model averaging approach to account for model uncertainty (Burnham \& Anderson 2002) by constructing a series of candidate models from all linear combinations of the nine explanatory variables $(n=512)$. We ranked these models by their AIC values, and calculated the AIC difference ( $\triangle \mathrm{AIC})$ and Akaike weight $\left(w_{i}\right)$ for each.

We also constructed a $95 \%$ confidence set of the models by adding together the Akaike weights, beginning with the model with the highest weight and continuing to add the next highest weight until the cumulative sum exceeded 0.95 (Burnham \& Anderson 2002).
The direction and magnitude of the effect size of each explanatory habitat variable were based on the modelaveraged parameter estimates from all models, weighted by the Akaike weights (Burnham \& Anderson 2002). To calculate the model-averaged parameter estimate, the parameter for each model was multiplied by the Akaike weight for that model. The weighted-average estimate is then the sum of this calculation for all 512 models. We calculated the uncertainty of the parameter estimates based on the unconditional standard error of each.

We used pseudo- $R^{2}$ as a measure of goodness-of-fit to determine how well the final averaged model for each species fitted the data. The pseudo- $R^{2}$ is a measure of the variance in the dependent variable (small mammal abundance) that is explained by the model, on a scale of 0 to 1 (Dobson 2002).

Spatial autocorrelation occurs when the value of a variable at one location can be predicted by the values of nearby locations (Legendre \& Legendre 1998). It is an indication that sampling units are not independent of one another. In this case, we wanted to see whether abundance of small mammals was better explained by the location of a site than the explanatory model of habitat variables. To investigate the influence of spatial autocorrelation in the models, we tested for spatial autocorrelation in the Pearson residuals of the abundance of each small mammal species at each site using the spatial autocorrelation statistic Moran's I, and a Z-test calculated in ArcGIS version 9.3.

\section{Vegetation structure}

We used a multivariate analysis of variance (MANOVA) to determine whether fire frequency affected habitat structure, with number of fires as the fixed factor and all measured habitat characteristics as the dependent variables. Prior to analysis, we assessed all habitat data for normality using the Kolmogorov-Smirnov test, and tested for homogeneity of variance using Levene's test. All habitat data were normal and homogenous for variance (Levene's test, $P>0.05$ ). Tukey's HSD post hoc test was used to investigate which of the habitat variables differed between fire frequencies. Data were analysed using SPSS version 19.0.

\section{RESULTS}

Over 2700 trap-nights, we captured 35 individuals of Antechinus stuartii and 40 Antechinus flavipes. There was a significant association between number of fires and species of antechinus $\left(\chi^{2}=28.647\right.$, d.f. $=3, P<$ 0.001 ; Fig. 2). There was a significant difference in relative abundances of the antechinus species between sites burned once and all other fire frequencies $(P<$ 0.001). We captured more Antechinus stuartii at sites burned once, but captured more Antechinus flavipes at sites burned more frequently.

The GLM model combinations showed a high level of model uncertainty, with 126 models for $A$. stuartii (Table 1), and 285 models for $A$. flavipes in the $95 \%$ confidence set (Table 2) $(\Sigma w \mathrm{i}=0.95)$. There were high

(C) 2014 The Authors

Austral Ecology (C) 2014 Ecological Society of Australia 
Table 1. Coefficients of the 10 best generalized linear models, with $\mathrm{AIC}_{\mathrm{c}}$ values, change in $\mathrm{AIC}_{\mathrm{c}}$ values $(\Delta)$ and Akaike weight $\left(w_{i}\right)$ of habitat variables influencing the abundance of Antechinus stuartii at the study sites

\begin{tabular}{lcccccccccccc}
\hline & & \multicolumn{1}{c}{ Canopy } & Density \\
Intercept & $\begin{array}{c}\text { Grass } \\
\text { cover }\end{array}$ & $1-15 \mathrm{~m}$ & cover & $\begin{array}{c}\text { Ground } \\
\text { cover }\end{array}$ & $\begin{array}{c}\text { Litter } \\
\text { depth }\end{array}$ & $\begin{array}{c}\text { Nectar } \\
\text { producing } \\
\text { plants }\end{array}$ & $\begin{array}{c}\text { No. } \\
\text { grass } \\
\text { trees }\end{array}$ & $\begin{array}{c}\text { Standing } \\
\text { dead trees }\end{array}$ & $\begin{array}{c}\text { Tree } \\
\text { hollows }\end{array}$ & AIC $_{c}$ & $\Delta$ & $w_{i}$ \\
\hline-1.9816 & - & 1.2870 & -2.2468 & - & - & - & - & -2.8806 & - & 36.3181 & 0.0000 & 0.5383 \\
-0.3030 & - & 1.2687 & - & - & 0.9997 & - & - & -0.5460 & - & 40.5857 & 4.2676 & 0.0637 \\
-0.1497 & - & 1.2042 & - & - & 1.2437 & - & - & - & - & 40.7989 & 4.4808 & 0.0573 \\
-1.9219 & - & - & -2.7954 & - & - & - & -2.8016 & - & 1.6897 & 41.2759 & 4.9578 & 0.0451 \\
-1.2553 & - & 1.1759 & -1.5205 & - & 0.3845 & - & - & -1.9574 & - & 41.8780 & 5.5600 & 0.0334 \\
-2.9255 & - & 1.6366 & -3.0242 & - & - & - & - & -3.7458 & -0.3560 & 41.9890 & 5.6710 & 0.0316 \\
-2.6054 & - & 1.3211 & -2.8634 & - & - & - & -0.3777 & -3.0959 & - & 42.1962 & 5.8782 & 0.0285 \\
-1.6754 & - & 1.1788 & -1.9981 & - & - & 0.0716 & - & -2.6185 & - & 42.5375 & 6.2194 & 0.0240 \\
-2.0088 & -0.0569 & 1.2949 & -2.2936 & - & - & - & - & -2.9297 & - & 42.5735 & 6.2554 & 0.0236 \\
-2.0019 & - & 1.2992 & -2.2682 & -0.0209 & - & - & - & -2.9121 & - & 42.5988 & 6.2807 & 0.0233 \\
\hline
\end{tabular}

Table 2. Coefficients of the 10 best generalized linear models, with $\mathrm{AIC}_{\mathrm{c}}$ values, change in $\mathrm{AIC}_{\mathrm{c}}$ values $(\Delta)$ and $\mathrm{Akaike}$ weight $\left(w_{i}\right)$ of habitat variables influencing the abundance of Antechinus flavipes at the study sites

\begin{tabular}{|c|c|c|c|c|c|c|c|c|c|c|c|c|}
\hline Intercept & $\begin{array}{c}\text { Canopy } \\
\text { cover }\end{array}$ & $\begin{array}{l}\text { Density } \\
1-1.5 \mathrm{~m}\end{array}$ & $\begin{array}{l}\text { Grass } \\
\text { cover }\end{array}$ & $\begin{array}{l}\text { Ground } \\
\text { cover }\end{array}$ & $\begin{array}{l}\text { Litter } \\
\text { depth }\end{array}$ & $\begin{array}{c}\text { Nectar } \\
\text { producing } \\
\text { plants }\end{array}$ & $\begin{array}{l}\text { No. } \\
\text { grass } \\
\text { trees }\end{array}$ & $\begin{array}{l}\text { Standing } \\
\text { dead } \\
\text { trees }\end{array}$ & $\begin{array}{c}\text { Tree } \\
\text { hollows }\end{array}$ & $\mathrm{AIC}_{\mathrm{c}}$ & $\Delta$ & $w_{i}$ \\
\hline 1.0485 & - & - & - & - & - & -0.6768 & - & - & 0.4426 & 52.7623 & 0.0000 & 0.2421 \\
\hline 1.0968 & - & - & - & - & - & -0.5038 & - & - & - & 54.5387 & 1.7764 & 0.0996 \\
\hline 0.9964 & - & - & - & - & - & -0.8488 & - & 0.3261 & 0.6009 & 54.7266 & 1.9643 & 0.0907 \\
\hline 1.0067 & - & - & - & -0.2877 & - & -0.6380 & - & - & 0.5196 & 55.6474 & 2.8851 & 0.0572 \\
\hline 1.0229 & - & 0.2017 & - & - & - & -0.8399 & - & - & 0.4637 & 56.6724 & 3.9101 & 0.0343 \\
\hline 1.0495 & - & - & - & - & - & -0.6745 & 0.1249 & - & 0.4524 & 57.0249 & 4.2626 & 0.0287 \\
\hline 1.0488 & - & - & -0.0976 & - & - & -0.6509 & - & - & 0.4403 & 57.2355 & 4.4732 & 0.0259 \\
\hline 1.0494 & - & - & - & - & 0.0548 & -0.6642 & - & - & 0.4359 & 57.4026 & 4.6404 & 0.0238 \\
\hline 1.0475 & -0.0487 & - & - & - & - & -0.6945 & - & - & 0.4626 & 57.4287 & 4.6664 & 0.0235 \\
\hline 1.0925 & 0.1592 & - & - & - & - & -0.4767 & - & - & - & 57.4381 & 4.6758 & 0.0234 \\
\hline
\end{tabular}

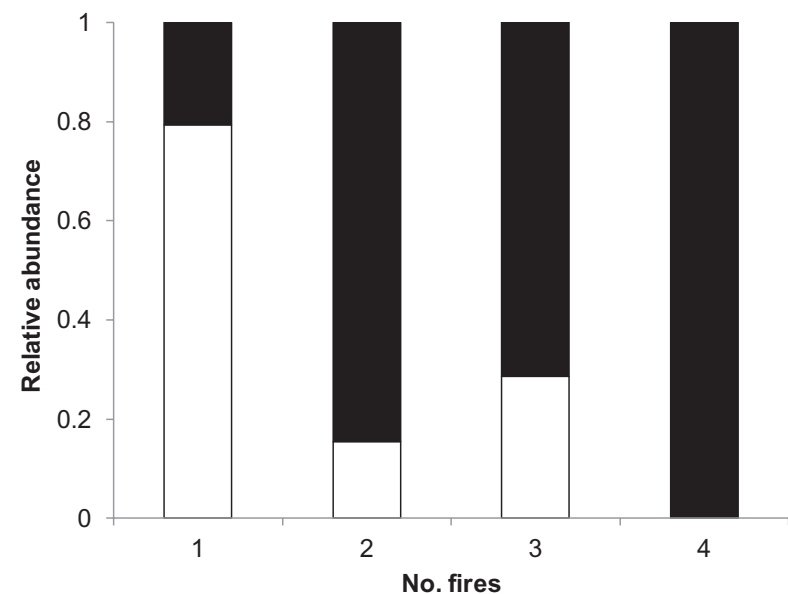

Fig. 2. Relative abundance of Antechinus flavipes (black bars) versus Antechinus stuartii (white bars) in sites of different fire frequencies.

(C) 2014 The Authors

Austral Ecology (C) 2014 Ecological Society of Australia levels of parameter uncertainty for most explanatory variables for $A$. stuartii in addition to the high level of model uncertainty, due to the low numbers of this species captured at some sites. We therefore used only those models with a $\triangle \mathrm{AIC}$ less than 2 (Burnham \& Anderson 2002) in the final averaged model for $A$. stuartii. Data were not spatially autocorrelated for the models for $A$. stuartii (Global Moran's $\mathrm{I}=0.008$, $\mathrm{Z}=0.439, P=0.661$ ) or $A$ flavipes (Global Moran's $\mathrm{I}=-0.209, \mathrm{Z}=-0.478, P=0.633)$.

The only major effect on $A$. stuartii abundance in the model was percentage grass cover, with which $A$. stuartii had a strong negative association (Fig. 3). All other variables were either inconsequential or had very large standard errors. Percentage shrub cover and number of nectar-producing plants had the strongest negative effect on $A$. flavipes abundance in the model, followed by litter depth (Fig. 4). The strongest positive 


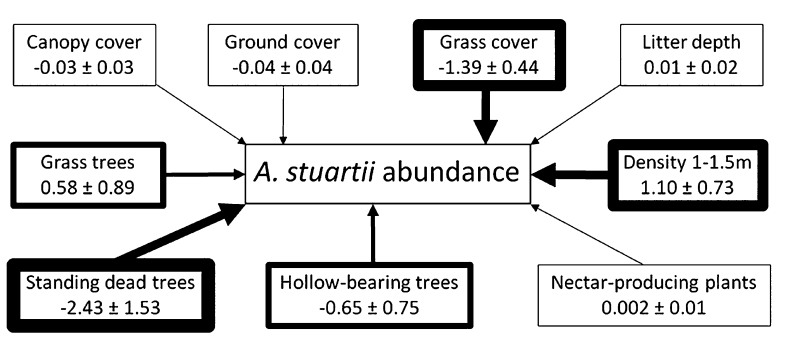

Fig. 3. Path diagram showing the average parameter estimate \pm standard error for each key explanatory variable of Antechinus stuartii abundance derived from all combinations of the regression models. Line width is weighted by the average parameter estimate.

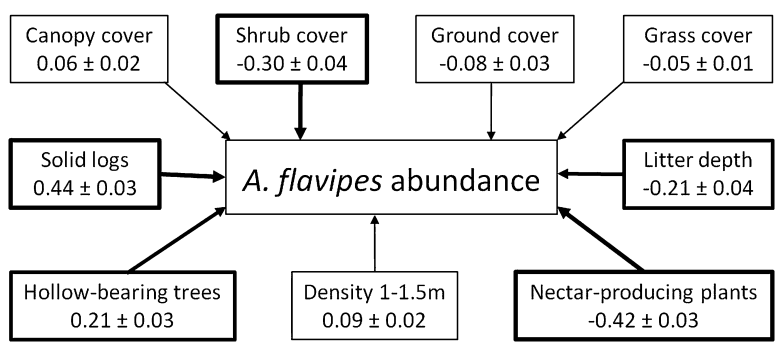

Fig. 4. Path diagram showing the average parameter estimate \pm standard error for each key explanatory variable of Antechinus flavipes abundance derived from all combinations of the regression models. Line width is weighted by the average parameter estimate.

associations with $A$. flavipes abundance were number of solid logs and number of hollow-bearing trees. There was a weak negative effect of ground cover and grass cover, and a weak positive effect of density at the $1-1.5 \mathrm{~m}$ level. The model had a good fit to the data $\left(R^{2}=0.96\right)$.

There was no difference between fire frequencies in terms of overall habitat structure (Pillai's trace $=1.843$ $\left.F_{24,9}=0.597, P=0.850\right)$. Univariate $F$ tests calculated for all variables showed that there was a significant effect of fire frequency on percentage ground cover $\left(F_{3,8}=4.305, P=0.044\right)$, mean log diameter $\left(F_{3,8}=\right.$ $6.467, P=0.016)$, and number of hollow-bearing trees $\left(F_{3,8}=6.327, P=0.017\right)$.

Tukey's HSD post hoc tests did not show any significant differences in ground cover between fire frequencies. There was however a trend for higher ground cover at 1 -fire sites than 4-fire sites $(P=0.06$; Fig. 5a). Logs at 3-fire sites were larger in diameter than those at 1 -fire sites $(P=0.06)$, and significantly larger than those in 2-fire $(P=0.035)$, and 4-fire $(P=0.016)$ sites (Fig. $5 b)$. There were significantly more hollow-bearing trees at 1-fire and 3-fire sites than at 2 -fire sites $(P=0.023, P=0.052$; Fig. $5 \mathrm{c})$.
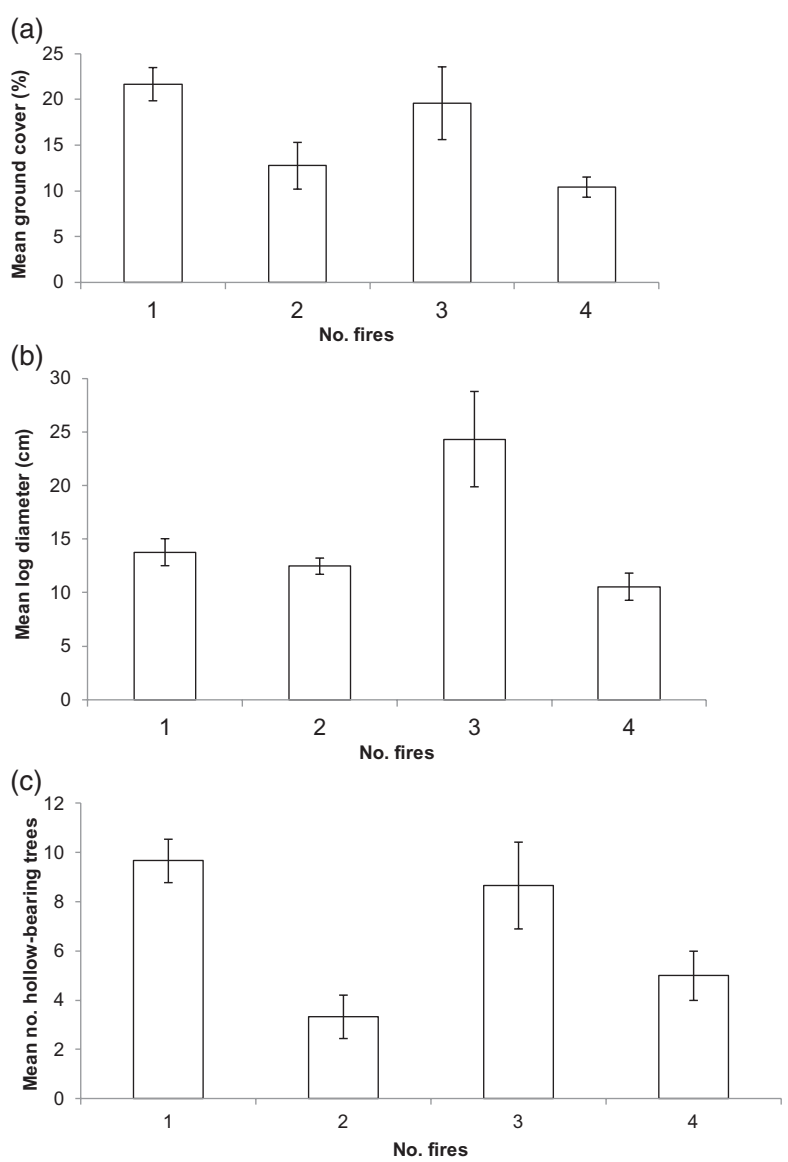

Fig. 5. Mean $( \pm S E)$ (a) percentage ground cover, (b) $\log$ diameter $(\mathrm{cm})$ and $(\mathrm{c})$ number of hollow-bearing trees at sites of different fire frequency.

\section{DISCUSSION}

Theory predicts that ecologically similar species should partition habitats to minimize competition (Schoener 1974, 1986). We found a pattern of reciprocal abundance of the two antechinus species related to fire frequency. At sites burned only once, $A$. stuartii was much more abundant than $A$. flavipes. Under higher fire frequencies $A$. flavipes was more abundant than $A$. stuartii, and $A$. stuartii was absent from sites burned four times. These results suggest that fire frequency influences the distribution and abundance of the two antechinus species. The question of how fire influences the distribution of these two species is more difficult to answer.

Niche partitioning by sympatric species occurs when competition forces each species to specialize in the niche dimension (e.g. a resource or habitat type) in which it has a competitive advantage, and to relinquish those in which another species outcompetes it (Schoener 1974, 1986). Therefore, for this to be an 
explanation of the patterns of distribution observed in our study, a shift in the competitive advantage of the two antechinus species must occur as a function of fire frequency. Potentially, such competitive interactions may be mediated via fire-induced effects on vegetation structure. In support of this, we found that fire frequency exerted subtle effects on vegetation structure, with a trend for lower ground cover at sites burned more frequently. This pattern is consistent with the reduction in vegetation complexity that tends to occur with more frequent fire (Gill and Catling 2002; Keith et al. 2002b).

The fact that $A$. stuartii was absent from the mostfrequently burned sites makes sense given that this species preferentially utilizes habitats with dense ground cover (Bennett 1993; Knight \& Fox 2000; Crowther \& Braithwaite 2008). Whilst ground cover was not a significant explanatory variable in our model for $A$. stuartii, it should be noted that this model was poor due to the low numbers or total absence of the species at some sites. The dominance of $A$. flavipes at frequently-burned sites can be explained by its ability to exploit resources in more open environments (Sumner \& Dickman 1998; Crowther 2002, 2008); this species displayed a slight negative association with ground cover in the model. Hence, the subtle effects of fire frequency on ground cover may help to explain the patterns of abundance that we observed, although more extensive sampling of habitat variables is needed to further elucidate the underlying causes of this pattern.

The dental and cranial morphology of $A$. flavipes allows it to feed on a greater range of prey than other antechinus species, which is one explanation for its ability to survive in a wide range of habitats (Van Dyck 1982; Coates 1995). The broader dietary niche and habitat use of $A$. flavipes may allow it to tolerate a wider range of fire frequencies than $A$. stuartii because it is more readily able to shift its resource use. The competitive ability of the more specialized $A$. stuartii would therefore be decreased under higher fire frequencies, yet it would itself displace the more generalist $A$. flavipes from lower fire-frequency habitats.

Differential habitat use in sympatry has previously been demonstrated to occur between $A$. flavipes and other antechinus species. Dickman (1986) examined competition between narrowly sympatric $A$. flavipes and $A$. agilis (the latter then considered to be conspecific with $A$. stuartii). Where they occurred sympatrically, both $A$. agilis and $A$. flavipes exhibited smaller habitat niche breadths than in allopatry; $A$. flavipes was more restricted to open, rocky areas, whilst $A$. agilis was typically captured in areas of dense vegetation. This suggested the two species mutually restrict each other's access to certain habitat types.

(C) 2014 The Authors

Austral Ecology (C) 2014 Ecological Society of Australia
Similarly, habitat shift has been observed in $A$. flavipes as a result of competitive interactions with $A$. subtropicus (previously A. stuartii; Van Dyck \& Crowther 2000) near the interface of the two species ranges in south-east Queensland (Van Dyck 1982). In this region, $A$. subtropicus mainly occurs in vine forests, preferring areas of dense vegetation and rotting logs, and avoiding habitats with sparse ground cover (Braithwaite 1973). Antechinus flavipes occurs in a wide range of drier habitats types outside the vine forests where $A$. subtropicus is concentrated, yet utilizes vine forests and other dense vegetation in areas where A. subtropicus is absent. Hence the presence of $A$. subtropicus appears to result in habitat shift by $A$. flavipes (Van Dyck 1982).

Our study is the first to suggest an influence of fire frequency on competitive interactions between sympatric antechinus species. Our results indicate that differential habitat use, mediated by fire-frequency, could represent a mechanism allowing coexistence of $A$. stuartii and $A$. flavipes. It would certainly appear that fire regimes have an important influence on the distribution of these two species, for which Yengo National Park represents one of the few areas of true sympatry (Crowther 2008; Crowther \& Braithwaite 2008). The mixture of fire intervals that exist naturally in heterogeneous landscapes could play a role in facilitating the coexistence of the two antechinus species at the intersection of their ranges.

Experimental studies, such as removal experiments (e.g. Higgs \& Fox 1993), are required to demonstrate competitive interactions between the two species (Underwood 1986). In addition, experimental manipulation of habitat structure (e.g. Monamy \& Fox 2000) could help to better explain which habitat features were driving the patterns of abundance that we observed.

It is important to note that as the time-since-fire increases at our study sites, the patterns we observed will likely change. At all sites, the vegetation density will likely increase with increasing time since last the fire, and therefore $A$. flavipes may decline at all sites and the observed patterns may no longer be evident in the future. Future study could explore the outcome of increasing time-since-fire on the abundances of the two antechinus species.

The potential ecological impacts of imposing any particular prescribed fire regime are complex and difficult to predict. The results of our study provide an indication as to the possible effects of introducing higher-frequency versus lower-frequency prescribed fire regimes. In Yengo National Park, $A$. stuartii was absent from sites burned four times in forty years. Considering that this is a lower burning frequency than that which is typical of prescribed burning regimes (often as frequent as every five years in the Sydney region; Benson 1985), it seems likely that 
frequent burning in a similar ecological community could have detrimental impacts on this species.

Our study also provides an indication as to the possible effects of the predicted increase fire frequencies in south-eastern Australia resulting from climate change (Hughes 2003; Bradstock et al. 2008). Populations that exist near their fire-frequency extinction threshold are at risk of substantial declines as a result of climate change (Cary 2002). It is possible that increasing fire frequency as a result of climate change could lead to the decline or local extinction of $A$. stuartii in the Yengo region, especially if $A$. flavipes proves to be competitively superior under higher fire-frequencies.

Our study provided insights into the complexities of small mammal responses to fire. By mediating niche-separation, fire frequency could be an important factor allowing the coexistence of similar species. This possibility has not previously been explored, yet it could have important implications for management: implementing a new fire regime for either hazard reduction or ecological purposes could have unintended consequences via its impacts on interactions between species. Until we have a better understanding of how fire frequency affects multiple species, a precautionary approach may be best for sustaining biodiversity.

\section{ACKNOWLEDGEMENTS}

We thank N. D'Souza, J. Edington, C. Spraggon, D. Logendran, X. Clark, M. Tan, M. Kam, A. Long, C. Talty, N. Tong, A. Shaw, A. Rainbow, L. Tilly and N. Coggan for assistance in the field. R. Colbourne and A. Horwood (NSW NPWS) gave advice and provided site access. This study was carried out under Animal Ethics Licence L04/3-2010/3/5288 and National Parks and Wildlife Scientific licence S13117.

\section{REFERENCES}

Abramsky Z., Dyer M. I. \& Harrison P. D. (1979) Competition among small mammals in experimentally perturbed areas of the shortgrass prairie. Ecology 60, 530-6.

Akaike H. (1983) Information measures and model selection. Bulletin of the International Statistical Institute, Proceedings of the 44th Session. pp. 277-91.

Andersen A. N., Cook G. D., Corbett L. K. et al. (2005) Fire frequency and biodiversity conservation in Australian tropical savannas: implications from the Kapalga fire experiment. Austral Ecol. 30, 155-67.

Arrizabalaga A., Montagud E. \& Fons R. (1993) Post-fire succession in small mammal communities in the Montserrat Massif (Catalonia, Spain). In: Fire in Mediterranean Ecosystems (eds L. Trabaud \& R. Prodon) pp. 281-91. Commission of the European Communities, Brussels.

Bennett A. F. (1993) Microhabitat use by the long-nose potoroo, Potorous tridactylus, and other small mammals in remnant forest vegetation of south-western Victoria. Wildl. Res. 20, 267-85.

Benson D. H. (1985) Maturation periods for fire-sensitive shrub species in Hawkesbury sandstone vegetation. Cunninghamia 1, 339-49.

Bond W. J. \& Keeley J. E. (2005) Fire as a global 'herbivore': the ecology and evolution of flammable ecosystems. Trends Ecol. Evol. 20, 387-94.

Bond W. J. \& Van Wilgen B.W. (1996) Fire and Plants. Chapman \& Hall, London.

Bradfield G. E. (1981) Component analysis of fire patterns in open eucalypt forest. Aust. F. Ecol. 6, 99-109.

Bradstock R. (1981) Our phoenix flora. Aust. Nat. Hist. 20, 223-6.

Bradstock R. A. (2008) Effects of large fires on biodiversity in south-eastern Australia: disaster or template for diversity? Int. F. Wildl. Fire 17, 809-22.

Bradstock R. A., Williams J. E. \& Gill M. A. (2002) Flammable Australia: The Fire Regimes and Biodiversity of a Continent. Cambridge University Press, Cambridge.

Bradstock R., Davies I., Price O. \& Cary G. (2008) Effects of climate change on bushfire threats to biodiversity, ecosystem processes and people in the Sydney region. Final Report to the New South Wales Department of Environment and Climate Change. University of Wollongong, Faculty of Science, Centre for Environmental Risk Management of Bushfires, Wollongong, NSW.

Braithwaite R. W. (1973) An Ecological Study of Antechinus stuartii (Marsupialia: Dasyuridae). University of Queensland, Brisbane.

Briani D. C., Palma A. R. T., Vieira E. M. \& Henriques R. P. B. (2004) Post-fire succession of small mammals in the Cerrado of central Brazil. Biodivers. Conserv. 13, 1023-37.

Burnham K. P. \& Anderson D. R. (2002) Model Selection and Multimodel Inference: A Practical Information-theoretic Approach, 2nd edn. Springer, New York.

Cary G. J. (2002) Importance of a changing climate for fire regimes in Australia. In: Flammable Australia: The Fire Regimes and Biodiversity of a Continent (eds R. A. Bradstock, J. E. Williams \& A. M. Gill) pp. 26-46. Cambridge University Press, Cambridge.

Cary G. J. (2005) Research priorities arising from the 2002-2003 bushfire season in south-eastern Australia. Aust. For. 68, 104-11.

Cary G. J. \& Morrison D. A. (1995) Effects of fire frequency on plant-species composition of sandstone communities in the Sydney region - combinations of inter-fire intervals. Aust. F. Ecol. 20, 418-26.

Christensen P. E., Recher H. \& Hoare J. (1981) Responses of open forest to fire regimes. In: Fire and the Australian Biota (eds A. Gill, R. Groves \& I. Noble) pp. 367-94. Australian Academy of Science, Canberra.

Coates T. (1995) Reproductive ecology of the yellow-footed antechinus, Antechinus flavipes (Waterhouse), in north east Victoria (PhD Dissertation). Monash University, Melbourne, Victoria, Australia.

Collins S. L. \& Wallace L. L. (1990) Fire in North American Tallgrass Prairies. University of Oklahoma Press, Norman.

Crowther M. S. (2002) Distributions of species of the Antechinus stuartii- $A$. flavipes complex as predicted by bioclimatic modelling. Aust. F. Zool. 50, 77-91.

Crowther M. S. (2008) Yellow-footed Antechinus Antechinus flavipes. In: Mammals of Australia (eds S. Van Dyck \& R. Strahan) pp. 86-8. New Holland, Sydney.

Crowther M. S. \& Braithwaite R. W. (2008) Brown Antechinus Antechinus stuartii. In: The Mammals of Australia 
(eds S. Van Dyck \& R. Strahan) pp. 94-6. New Holland, Sydney.

DeBano L., Neary D. G. \& Ffolliott P. F. (1998) Fire's Effects on Ecosystems. John Wiley \& Sons, New York.

Dickman C. R. (1986) Niche compression - two tests of an hypothesis using narrowly sympatric predator species. Aust. F. Ecol. 11, 121-34.

Dobson A. J. (2002) An Introduction to Generalized Linear Models, 2nd edn. Chapman \& Hall/CRC, Boca Raton.

Dueser R. D. \& Hallett J. G. (1980) Competition and habitat selection in a forest-floor small mammal fauna. Oikos 35, 293-7.

Fons R., Grabulosa I., Feliu C., Mas-Coma S. \& Galánpuchades M. T. (1993) Postfire dynamics of small mammals community in a Mediterranean forest (Quercus suber). In: Fire in Mediterranean Ecosystems (eds L. Trabaud \& R. Prodon) pp. 259-70. Commission of the European Communities, Brussels.

Fox B. J. (1982a) Fire and mammalian secondary succession in an Australian coastal heath. Ecology 63, 1332-41.

Fox B. J. (1982b) A review of dasyurid ecology and speculation on the role of limiting similarity in community organisation. In: Carnivorous Marsupials (ed. M. Archer) pp. 97-116. Royal Zoological Society NSW, Sydney.

Fox B. J. (1983) Mammal species diversity in Australian heathlands: the importance of pyric succession and habitat diversity. In: Mediterranean-type Ecosystems: The Role of Nutrients (eds E. J. Kruger, D. T. Mitchell \& J. U. M. Jarvis) pp. 473-89. Springer-Verlag, Berlin.

Fox B. J. (1990) Changes in the structure of mammal communities over successional time scales. Oikos 59, 321-9.

Fox B. J. \& Fox M. D. (1984) Small-mammal recolonization of open-forest following sand mining. Aust. F. Ecol. 9, 241-52.

Fox B. J. \& McKay G. M. (1981) Small mammal responses to pyric successional changes in eucalypt forest. Aust. F. Ecol. 6, $29-41$.

Fox M. D. \& Fox B. J. (1987) The role of fire in the scleromorphic forests and shrublands of eastern Australia. In: The Role of Fire in Ecological Systems (ed. L. Trabaud) pp. 23-48. SPB Academic Publishing, The Hague.

Friend G. (1999) Fire and faunal response patterns - a summary of research findings. In: Management of Fire for the Conservation of Biodiversity - Workshop Proceedings (eds G. Friend, M. Leonard, A. MacLean \& I. Sieler) pp. 39-45. Department of Natural Resources and Environment, Melbourne.

Friend G. R. (1993) Impact of fire on small vertebrates in mallee woodlands and heathlands of temperate Australia - a review. Biol. Conserv. 65, 99-114.

Gilbert J. (1959) Forest succession in the Florentine Valley, Tasmania. Papers Proc. R. Soc. Tas. 93, 129-51.

Gill A. (1975) Fire and the Australian flora: a review. Aust. For. 38, 4-25.

Gill A. M. \& Catling P. (2002) Fire regimes and biodiversity of forested landscapes of southern Australia. In: Flammable Australia: the Fire Regimes and Biodiversity of a Continent (eds R. A. Bradstock, J. E. Williams \& M. A. Gill) pp. 351-69. Cambridge University Press, Cambridge.

Gill A., Groves R. \& Noble I. (1981) Fire and the Australian Biota. Australian Academy of Science, Canberra

Goodyear N. C. (1992) Spatial overlap and dietary selection of native rice rats and exotic black rats. F. Mammal. 73, 186200.
Grant P. (1978) Competition between species of small mammals. In: Populations of Small Mammals Under Natural Conditions (ed. D. P. Snyder) pp. 38-51. Pymatuning Laboratory of Ecology, University of Pittsburgh, Pittsburgh, PA.

Green R. H. (1979) Sampling Design and Statistical Methods for Environmental Biologists. Wiley, New York.

Hammill K. \& Bradstock R. (2008) Biodiversity responses to fire regimes under climate change. Final report to the Environmental Trust on research project 2004 RD/0104. Department of Environment and Climate Change NSW \& the University of Wollongong, NSW.

Hersteinsson P. \& MacDonald D. W. (1992) Interspecific competition and the geographical distribution of red and Arctic foxes Vulpes Vulpes and Alopex lagopus. Oikos 64, 50515.

Higgs P. \& Fox B. J. (1993) Interspecific competition: a mechanism for rodent succession after fire in wet heathland. Aust. f. Ecol. 18, 193-201.

Hobbs R. (2002) Fire regimes and their effects in Australian temperate woodlands. In: Flammable Australia: The Fire Regimes and Biodiversity of a Continent (eds R. A. Bradstock, J. E. Williams \& A. M. Gill) pp. 305-26. Cambridge University Press, Cambridge.

Hughes L. (2003) Climate change and Australia: trends, projections and impacts. Austral Ecol. 28, 423-43.

Irvin M., Westbrooke M. \& Gibson M. (2003) Effects of repeated low-intensity fire on terrestrial mammal populations of a mixed eucalypt foothill forest in south-eastern Australia. Department of Sustainability and the Environment Fire Management Research Report 63.

Keith D. A., McCaw W. L. \& Whelan R. J. (2002a) Fire regimes in Australian heathlands and their effects on plants and animals. In: Flammable Australia: The fire Regimes and Biodiversity of a Continent (eds R. A. Bradstock, A. M. Gill \& J. E. Williams) pp. 199-237. Cambridge University Press, Cambridge.

Keith D. A., Williams J. E. \& Woinarski J. C. Z. (2002b) Fire management and biodiversity conservation: key approaches and principles. In: Flammable Australia. The Fire Regimes and Biodiversity of a Continent (eds R. A. Bradstock, J. E. Williams \& A. M. Gill) pp. 401-28. Cambridge University Press, Cambridge.

Kelly L. T., Nimmo D. G., Spence-Bailey L. M. et al. (2012) Managing fire mosaics for small mammal conservation: a landscape perspective. F. Appl. Ecol. 49, 412-21.

Kelt D. A., Taper M. L. \& Meserve P. L. (1995) Assessing the impact of competition on community assembly - a casestudy using small mammals. Ecology 76, 1283-96.

Knight E. H. \& Fox B. J. (2000) Does habitat structure mediate the effects of forest fragmentation and human-induced disturbance on the abundance of Antechinus stuartii? Aust. F. Zool. 48, 577-95.

Krebs C. J. (1966) Demographic changes in fluctuating populations of Microtus californicus. Ecol. Monogr. 36, 23973.

Krefting L. W. \& Ahlgren C. (1974) Small mammals and vegetation changes after fire in a mixed conifer-hardwood forest. Ecology 55, 1391-8.

Legendre P. \& Legendre L. (1998) Numerical Ecology, 2nd edn. Elsevier Science, Amsterdam.

Luo J. \& Fox B. J. (1996) Seasonal and successional dietary shifts of two sympatric rodents in coastal heathland: a possible mechanism for coexistence. Aust. F. Ecol. 21, 121-32. 
M'Closkey R. T. \& Fieldwick B. (1975) Ecological separation of sympatric rodents (Peromyscus and Microtus). F. Mammal. 56, 119-29.

Meserve P. L. (1981) Resource partitioning in a Chilean semi-arid small mammal community. F.Anim. Ecol. 50, 74557.

Monamy V. \& Fox B. J. (2000) Small mammal succession is determined by vegetation density rather than time elapsed since disturbance. Austral Ecol. 25, 580-7.

Morrison D. A., Gary G. J., Pengelly S. M. et al. (1995) Effects of fire frequency on plant species composition of sandstone communities in the Sydney region: inter-fire interval and time-since-fire. Aust. F. Ecol. 20, 23947.

NPWS (2003) The Bioregions of New South Wales: their biodiversity, conservation and history. NSW National Parks and Wildlife Service, Hurstville.

Ojeda R. (1989) Small mammal responses to fire in the mount desert, Argentina. f. Mammal. 70, 416-20.

Price M. V. \& Waser N. (1984) On the relative abundance of species: postfire changes in a coastal sage scrub rodent community. Ecology 65, 1161-9.

Quinn R. D. (1979) Effects of fire on small mammals in the chaparral. In: Cal-Neva Wildife Transactions (ed. D. L. Koch) pp. 125-33. Western Section of the Wildlife Society, Smartsville, CA.

Rosenzweig M., Smigel B. \& Kraft A. (1975) Patterns of food, space and diversity. In: Rodents in Desert Environments (eds I. Prakash \& P. K. Gosh) Monographiae Biologicae 28, pp. 241-68. Dr W. Junk, The Hague.

Schoener T. W. (1974) Resource Partitioning in Ecological Communities. Science 185, 27-39.

Schoener T. W. (1986) Resource partitioning. In: Community Ecology: Pattern and Process (eds J. Kikkawa \& D. J. Anderson) pp. 91-126. Blackwell Scientific Publications, Melbourne.

Siddiqi M. Y., Carolin R. C. \& Myerscough P. J. (1976) Studies in the ecology of coastal heath in New South Wales, Australia. Part 3. Regrowth of vegetation after fire. Proc. Linn. Soc. NSW 101, 53-63.

Spencer R. J. \& Baxter G. S. (2006) Effects of fire on the structure and composition of open eucalypt forests. Aust. Ecol. 31, 638-46.
Sumner J. \& Dickman C. R. (1998) Distribution and identity of species in the Antechinus stuartii- $A$. flavipes group (Marsupialia: Dasyuridae) in south-eastern Australia. Aust. f. Zool. 46, 27-41.

Tasker E. \& Dickman C. (2004) Small mammal community composition in relation to cattle grazing and associated burning in eucalypt forests of the Northern Tablelands of New South Wales. In: Conservation of Australia's Forest Fauna, 2nd edn (ed. D. Lunney) pp. 721-40. Royal Zoological Society of NSW, Sydney.

Underwood A. J. (1986) The analysis of competition by field experiments. In: Community Ecology: Pattern and Process (eds J. Kikkawa \& D. J. Anderson) pp. 240-68. Blackwell Scientific Publications, Melbourne.

Van Dyck S. (1982) The relationships of Antechinus stuartii and A. flavipes (Dasyuridae, Marsupialia) with special reference to Queensland. In: Carnivorous Marsupials (ed. M. Archer) pp. 723-66. Royal Zoological Society of New South Wales, Sydney.

Van Dyck S. \& Crowther M. S. (2000) Reassessment of northern representatives of the Antechinus stuartii complex (Marsupialia: Dasyuridae): A. subtropicus sp. nov. and $A$. adustus new status. Mem. Queensl. Mus. 45, 611-35.

Vieira E. M. (1999) Small mammal communities and fire in the Brazilian Cerrado. F. Zool. 249, 75-81.

Whelan R. J. (1995) The Ecology of Fire. Cambridge University Press, Cambridge.

Whelan R. J., Rodgerson L., Dickman C. R. \& Sutherland E. F. (2002) Critical life cycles of plants and animals: developing a process-based understanding of population changes in fire-prone landscapes. In: Flammable Australia: The Fire Regimes and Biodiversity of a Continent (eds R. A. Bradstock, J. E. Williams \& A. M. Gill) pp. 94-124. Cambridge University Press, Cambridge.

Wirtz W. O. II, Hoekman D., Muhm J. R. \& Souza S. L. (1988) Postfire rodent succession following prescribed fire in southern California chaparral. In: Management of Amphibians, Reptiles, and Small Mammals in North America (eds R. C. Szaro, K. E. Severson \& D. R. Patton) pp. 333-9. Rocky Mountain Forest and Range Experiment Station, U.S. Department of Agriculture, Forest Service, Flagstaff, AZ. General Technical Report RM-166. 